\title{
Povl Ole Fanger's impact ten years later
}

d'Ambrosio Alfano, Francesca Romana; Olesen, Bjarne W.; Palella, Boris Igor

\section{Published in:}

Energy and Buildings

Link to article, DOI:

10.1016/j.enbuild.2017.07.052

Publication date:

2017

Document Version

Peer reviewed version

Link back to DTU Orbit

Citation $(A P A)$ :

d'Ambrosio Alfano, F. R., Olesen, B. W., \& Palella, B. I. (2017). Povl Ole Fanger's impact ten years later. Energy and Buildings, 152, 243-249. https://doi.org/10.1016/j.enbuild.2017.07.052

\section{General rights}

Copyright and moral rights for the publications made accessible in the public portal are retained by the authors and/or other copyright owners and it is a condition of accessing publications that users recognise and abide by the legal requirements associated with these rights.

- Users may download and print one copy of any publication from the public portal for the purpose of private study or research.

- You may not further distribute the material or use it for any profit-making activity or commercial gain

- You may freely distribute the URL identifying the publication in the public portal

If you believe that this document breaches copyright please contact us providing details, and we will remove access to the work immediately and investigate your claim 


\title{
Povl Ole Fanger's Impact Ten Years Later
}

\author{
Francesca Romana d'AMBROSIO ALFANO \\ DIIn - Dipartimento di Ingegneria Industriale, Università degli Studi di Salerno \\ Via Giovanni Paolo II 132, 84084 Fisciano (Salerno), Italy
}

\section{Bjarne Wilkens OLESEN}

International Centre for Indoor Environment and Energy - Department of Civil Engineering Nils Koppels Alle, Building 402, DK-2800 Lyngby, Denmark

\section{Boris Igor PALELLA}

DII - Dipartimento di Ingegneria Industriale, Università degli Studi di Napoli Federico II Piazzale Vincenzo Tecchio 80, 80125 Naples, Italy

Corresponding author: phone +39 0817682618; fax +39 0812390364; email palella@unina.it

\begin{abstract}
This paper pays tribute to Povl Ole Fanger, the late professor at the Technical University of Denmark. His scientific studies, focused on the main parameters affecting indoor environmental quality, have inspired (and still inspire) professional design engineers and academic researchers on human thermal comfort and indoor air quality over the last five decades. In addition, he strongly contributed to the creation of a "European School" that addressed engineering issues and was well integrated with the American School, which was characterised (at that time) by a physiological approach. Ten years after his death, this paper is a memorial of his research in the field of thermal comfort and some aspects of indoor air quality. Only the original papers of this Danish scientist will be discussed. The analysis of each single topic of his research and of its impact on past and present research would require more space than would be available in a review article. The authors are confident that the research described in this paper will serve as a beacon for researchers working on thermal comfort now and in the future.
\end{abstract}

Keywords: thermal comfort; thermal environments; moderate environments; PMV; PPD; comfort 
indices.

\section{Introduction}

Povl Ole Fanger was born in Vejlby, Denmark on 16 July 1934. His personal history is quite unknown, but hundreds of papers contributing to our knowledge of thermal comfort and indoor air quality document his academic history. His $P M V$ and $P P D$ indices for thermal comfort assessment, and his olf and decipol units for indoor air quality, are the basis for most standards in the field of indoor climate. Fanger's academic history was reconstructed on the basis of the bibliographic archives of the InEQualitES (Indoor Environmental Quality and Energy Saving, an Italian research team composed by the Authors). This memorial paper is addressed to researchers in the field of the ergonomics of the thermal environment, and only the original papers by this Danish scientist will be discussed. The analysis of each single topic of his research and of the impacts on past and present researchers would require more space than is available in a common review article. The authors have separated the review article into successive decades, starting from the seventies up to his death in 2006. The authors are confident that his life's work will serve as a beacon for researchers working on thermal comfort.

\section{Early studies}

Fanger began his studies of thermal comfort in the 1960s. His first results were published in 1967 in Volume 73 of ASHRAE Transactions with the title: Calculation of thermal comfort: introduction of a basic comfort equation [1]. In this paper (based on extensive experimental studies carried out at the Kansas State University and financed by ASHRAE) Fanger criticized the American approach to thermal comfort which considered only one level of metabolic rate, one kind of clothing (e.g. summer), air temperature equal to mean radiant temperature and no air movement. As an alternative, he proposed a new method based on experimental investigations carried out on a large sample of young people. The key finding of these studies was that the comfort sensation could be related to the mean skin temperature and the heat loss by evaporation (both related to the metabolic rate). This novel method, universally known as the comfort equation or Fanger's equation, was based on the heat balance of the human body under certain boundary conditions. This paper also reported comfort lines, which define comfort conditions when environmental parameters (air temperature, mean radiant temperature, air velocity and humidity) and personal parameters (metabolic rate and clothing insulation) are changed.

Some American reviewers of the original 1967 research paper criticised Fanger's approach extensively [1]. In particular, Boyer considered that a comfort equation that did not derive a comfort index 
was useless and stressed the need to take into account other environmental parameters (e.g. atmospheric composition, barometric pressure, lighting and acoustic parameters). Other criticisms were the fact that comfort lines provided information only about changes in comfort conditions. J.W. Dunham criticised the omission of the vapour diffusion resistance of clothing. A.P. Gagge considered that it was impossible to extend the physiological hypotheses forming the basis of Fanger's model (i.e. skin temperature and sweat rate as a function of metabolic rate) over their range of validation (air temperature values from 16 to $22^{\circ} \mathrm{C}$ ) without further experimental investigation. In addition, he disapproved of the long calculation times required for the solution of the heat balance equation (at that time 2 hours of machine time were required).

Fanger accepted all these observations and easily defended his reasoning. In particular, he replied that none of the omitted environmental parameters affected thermal comfort and that similar comfort lines appeared in ASHRAE Fundamentals (although only for one case). Concerning the lack of a comfort index, Fanger replied that he was attempting to consider pressure values under one bar. He pointed out that HVAC engineers are in practice interested in the air temperature value required to ensure thermal comfort rather than in a comfort index.

Concerning the effect of clothing vapour diffusion resistance, a topic that had been studied by Gagge's team at the J.B. Pierce Foundation since the 1930s [2], Fanger agreed that it was a very difficult issue, but largely irrelevant in moderate indoor environments.

The experimental results, obtained during his stay at Kansas State University and used as the basis of his findings, were published in a later paper [3].

\section{The book “Thermal Comfort"}

In 1970, a paper devoted to the results of research on the experimental equations for the calculation of the angle factors between the human body and horizontal and vertical walls [4] and the book entitled Thermal Comfort [5] were published almost simultaneously. As stressed in the preface, this book was addressed to engineers whose goal is to design thermal comfort condition in indoor environments and who are not trained in physiology, psychology or ergonomics issues.

The book has been universally recognised as a kind of bible by researchers involved in thermal comfort issues and it reports the results of all of the studies carried out at the DTU laboratories and at the Kansas State University laboratories. In particular, the studies on the effect of gender and age and the calculation of the angle factors and the mean radiant temperature are presented in the book. Most significantly, the book introduced the PMV (Predicted Mean Vote) as an overall comfort index, the PPD (Predicted Percentage Dissatisfied), presently used by ISO Standard 7730 [6], and defined the main parameters influencing sensations of local thermal discomfort. 


\section{The 70s}

A great deal of research was conducted on various topics (e.g. engineering, physiology and psychology issues) in order to reinforce the hypotheses proposed in Thermal Comfort and to investigate new facets of them. An interesting aspect of Fanger's research was that he always used the same experimental procedures. This enabled him to compare the various experiments and use one as a starting point for the other. In addition, one its great merits was experiments were usually carried out on on both male and female subjects.

\subsection{The influence of the effect of age, gender, adaptation, season and circadian rhythms on thermal comfort.}

The thermal response of subjects exposed to cold conditions was discussed in a paper dated 1971 [7]. Until that time, the topic had been studied only in the field and from the point of view of perception, without paying great attention to the thermal boundary conditions. Fanger concluded that acclimatisation to cold results in a preferred temperature value lower than that felt by people not usually exposed to cold environments. He tested 16 subjects chosen among workers from a meat packing industry in a laboratory setting at DTU. They preferred a mean ambient temperature that was $1{ }^{\circ} \mathrm{C}$ lower than the optimal temperature for other subjects exposed under the same conditions. Due to large individual differences this difference was not statistically significant.

The PMV index is based upon a heat balance equation of the human body adjusted by means of subjective measurements carried out on a homogeneous sample of about 1300 students in a climatic room (in USA at the KSU and in Denmark at the DTU). To investigate whether age, gender, adaptation, season and circadian rhythm had significant effects on the thermal environment preferred by man, Fanger published a study where the results obtained by other teams where compared with those obtained at the DTU [8]. Two different methods were adopted. In the first case, 8 or 10 subjects at a time were exposed to a constant thermal environment and were asked to vote on how they felt thermally. In the second, only one subject was exposed and was asked whether he preferred a warmer or cooler environment, then the ambient temperature was immediately changed according to his wishes. The main result of this study was that the same comfort conditions are preferred at all ages and under all conditions, independent of race, geographical location, during the night or day and during summer or winter [8].

As was observed by Fanger [9], the few studies carried out since the 60s devoted to the effect of colour on thermal sensation did not provide sufficient information on any possible effects on preferred ambient temperature. In addition, no research had been performed on the effects of noise on thermal 
comfort. To verify the effects of these two factors, he exposed a group of 16 sixteen college age subjects to two types of coloured light ('warm' red and 'cold' blue) and to two noise levels (low or high) in all four combinations. The colours in the room were determined mainly by the colour of the artificial lighting (no daylight was present in the environmental chamber). These experiments found that neither factor had any influence on comfort conditions. These experiments were carried out in a new climatic room constructed at DTU that was similar to the one at KSU University. In this way, the methodologies and the measurement methods of the two laboratories [11] were standardised. Clothing was also standardised, as KSU supplied the standard clothing ensemble to DTU.

\subsection{The hypothesis of mean skin temperature and sweat rate values as a function of the metabolic rate}

One of the main hypotheses forming the basis of Fanger's approach to comfort is assuming (as indicated by experimental data) that the skin temperature and sweat rate in a state of thermal comfort are related only to the activity level [1]. Later studies [12] further confirmed these hypotheses and showed that skin temperature values are lower than predicted only at high air temperature values.

In this period one of us (BWO), began working at the DTU.

The first co-authored paper by both Fanger and Olesen [13] was devoted to this topic. The authors found that in a state of thermal comfort the skin temperature distribution across the body surface is relatively uniform, with small differences for the head (warmer) and the extremities (cooler). They also found some gender differences, the distribution being less uniform in women, with skin temperatures on the feet being $2.1{ }^{\circ} \mathrm{C}$ lower than for men. In addition, the uniformity disappeared in the presence of winter clothing, due to the high thermal insulation of those parts of the body insulated by the clothing. This phenomenon did not affect the mean skin temperature value, because the increased skin temperatures of the insulated parts of the body were compensated by the reduced skin temperature of the uninsulated parts.

\subsection{The variation of comfort conditions with time}

This topic was studied from several perspectives in terms of the variation of preferred temperature as a function of the day [14], the hour [15], during day and night [16], in the morning and in the evening [17]. All experiments were carried out with the same procedure except for the first two (only men were involved). No differences in preferred temperature values were found by Fanger and his coworkers: only gender differences in skin temperature and the evaporation rate were observed. 


\subsection{Behavioural effects of thermal comfort}

This topic is still controversial, as are thermal effects on productivity. The first experiments were carried out at DTU and reported in a paper by Wyon et al. [18]. To understand the effects of temperature swings on mental work and thermal comfort, the authors carried out experimental runs in a special climatic chamber where air temperatures (which were kept equal to mean radiant temperature) were accurately designed to oscillate about preferred air temperatures. The objective measurements of the environmental parameters and the skin temperature were accompanied by subjective ratings obtained by means of special questionnaires on thermal sensation. Preliminary conclusions from this investigation were that mental work was improved by steady temperature while small and rapid swings were not tolerated.

The effects on the mental performance of adults under hot and cold conditions were reported in Langkilde et al. [19], four years after studies on children carried out by Wyon [20]. The investigation was based on performance tests and physiological measurements (e.g. mean skin temperature, rectal temperature, evaporative weight loss and air temperature) for several days at the same time of day $[15,21]$. The initial results revealed some reduction in performance under warm conditions. These results were extended to cold conditions, where it is possible to achieve thermal comfort by increasing clothing insulation values. The results [22] confirmed that there was no difference in performance between temperatures when comfort conditions were obtained in both by wearing different clothing. A gender difference was observed in terms of different skin temperatures and evaporation rates.

\subsection{Local thermal discomfort}

This issue was mentioned only briefly in the book "Thermal Comfort". Olesen et al. [23] reported the results of experiments (some of them from other laboratories) on local discomfort due to horizontal radiant asymmetry (from vertical walls). The first results on the draught rate for subjects exposed to airflows from directions other than frontal were reported in [24]. Another novelty was the use of a thermal manikin, developed at DTU by T. L. Madsen [25].

The basic concept was that air velocity variations can be balanced by air temperature changes to obtain comfort conditions. Experimental results demonstrated that the preferred temperature was not affected by the airflow direction. However, the turbulence intensity of the air movement had significant effects on local discomfort. This is still the basis for the present draught discomfort model [6]. In 1977, Fanger et al. [26] demonstrated that the frequency of velocity fluctuations affects the sensation of draft. In a later paper Olesen et. al. [27] described the first experimental series carried out at DTU on subjects and manikins in a climatic room aimed to assess local thermal discomfort due to vertical air temperature gradients. The results showed that people do not tolerate warm head and/or 
cold feet and that increasing the vertical air temperature difference decreases the impression of freshness. The paper reports a first attempt to predict the percentage dissatisfied due to this kind of discomfort.

\subsection{Thermal comfort and HVAC systems}

Ole Fanger never forgot that his research started by recognising that existing knowledge of thermal comfort was quite inadequate and unsuitable for practical applications and that the creation of thermal comfort for man is one of the principal aims in environmental engineering and indeed in the entire heating and air-conditioning industry.

A paper dated 1975 demonstrated that there are large individual differences between people [28]. Unfortunately, designers do not know which person will occupy a space so they design for an average occupant. This means that it is possible to design HVAC systems by referring to an average subject [27]. Another paper about cooling systems for industrial environments was published the same year [29]. The solution proposed by the authors of this paper was radiant cooling and an increase in air velocity values for outdoor air temperature values over $30^{\circ} \mathrm{C}$. In two other papers [30, 31] some studies with people were reported.

\subsection{Severe hot environments}

Studies of the thermal response of the body to severe hot environments are reported in a later paper [32]. The investigation was carried out in a special climatic room at the DTU where subjects were initially exposed to hot conditions, then to comfort conditions. The results showed the limits of the comfort equation in predicting the thermal state under hot-to-comfort transient conditions. In addition, the authors hypothesised a kind of temperature-dependent memory of the thermoregulatory system, which can be affected by the duration of the exposition. These results were used in the 70s and 80s for designing recovery rooms where it was recommended to use personal cooling systems provided with air jets.

\subsection{Vision for future research}

In a paper at the end of 70s in ASHRAE Transactions [33], Fanger reviewed research in the field by identifying the main topics of interest: local thermal discomfort, the relationship between productivity and thermal comfort and indoor air quality. 


\subsection{Thermal environment assessment}

In 1973, Fanger wrote a full paper entirely devoted to an assessment of thermal comfort in practice and for the first time introduced the concept of quality of the thermal environment [14] which is an issue still investigated at the international level. This paper summarised the state of the art in the field at that period and proposed the use of a special comfort meter [34], an integrated sensor for predicting thermal discomfort.

\section{The 80s}

In this decade, the Danish scientist continued to investigate the topics discussed above and started research in other fields. In addition, his fame grew increasingly and many times he was in demand worldwide to report the studies carried out at DTU [35, 36, 37].

\subsection{Local thermal discomfort}

Radiant asymmetry and draught were the main topics investigated.

Radiant asymmetry experiments were conducted in a climatic room provided with a radiant ceiling and are described in a first paper dated 1980 [38]. These results lead to the formulation of a chart for predicting the percentage dissatisfied due to horizontal radiant asymmetry. Comparison with earlier results [23] demonstrated a higher sensitivity compared to vertical asymmetry from warm ceilings. In a second paper [39], he discussed the same experiments and compared them with results obtained on a thermal manikin. Fanger discovered that a thermal manikin was more affected than subjects were by radiant asymmetry. This is because a subject, even when seated, can modify his position to reduce the area of the body that is irradiated. The results of these three papers were summarized in a third paper [40] which presented a full chart for the calculation of the percentage dissatisfied due to radiant asymmetry that is still used today.

The first model of a Draught Rate (DR) equation taking into account the mean air velocity, the turbulence intensity (the standard deviation of the air velocity) and the air temperature was reported in a paper dated 1986 [41]. Two years later Fanger's team [42, 43, 44] carried out studies of the characteristics of turbulent airflow in indoor spaces, and discovered the effects of the intensity of the turbulence on thermal sensation. In particular, Melikov et al. [44] discussed the DR model formulated by Christensen et al. [45] and based on the values of the air temperature, air velocity and turbulence intensity. This model is still used today [6]. 


\subsection{Clothing thermal insulation}

In 1982 Fanger's research team published the first paper devoted to the effects of clothing [46]: they proposed a novel photographic method estimating the clothing area factor and demonstrated that the clothing insulation value of a seated person is lower than for a standing person. These results were described in another paper [47] which also demonstrated how activity and the air velocity can both lead to a reduction of basic clothing insulation values.

\subsection{The effect of the humidity}

In two papers $[48,49]$ Fanger demonstrated that in moderate environments the humidity does not affect thermal comfort and that raised humidity increases the incidence of respiratory illnesses and while decreasing problems caused by static electricity. In addition, he hypothesised that the sensation of dryness in mucous membranes is mainly due to poor indoor air quality rather than to low humidity.

\subsection{Thermal comfort and heating systems}

To study the effects of heating systems on thermal comfort and energy requirements, Fanger and his team investigated nine different heating systems (e.g. radiators, radiant panels) in a climatic chamber at DTU [50]. The results [51, 52] showed that all nine heating systems were capable of providing uniform thermal conditions in the space, with some differences in terms of draught rate and vertical air temperature gradients. In addition, it was shown how PMV-PPD should be used to describe the thermal uniformity of a space.

\subsection{Thermal comfort Standards}

In a paper dated 1984, Fanger explained the importance of the new ISO Standard for moderate thermal environments [53] and insisted that a residual percentage dissatisfied was a physiological matter and not due to any incorrect design or management of HVAC systems. A methodology for the application of PMV and PPD indices was described in [54] and, finally, two special applications in clean rooms and sports facilities were discussed in [55] and [56], respectively. The first version of ISO 7730 Standard [57], based on early studies performed by his team, was issued in 1984. He anticipated its content in a paper issued the previous year [58] by discussing the charts it contained for the prediction of the percentages dissatisfied due to local discomfort [26, 27, 39, 45, 59, 60].

\subsection{Indoor Air Quality (IAQ)}

A paper devoted to the formulation of indices for the assessment of the IAQ (olf and decipol) was published in 1988 [61]. 


\section{The 90s}

During the 1990s, Fanger increased his research on indoor air quality. Concerning thermal comfort, he demonstrated that step-changes (up and down) of operative temperature are felt instantaneously but in different ways. In case of up-steps, a steady state is experienced almost immediately, whereas in down-steps, thermal sensation drops immediately to a level cooler than the later steadystate sensation, which is reached within 30 minutes [62].

This topic was also studied at DTU by de Dear et al. [63] who formulated a sensible heat transfer numerical model to assess variations of skin temperature following a step change in the operative temperature. Numerical simulations were compared with experiments conducted at DTU but without obtaining fully satisfactory results.

A later paper based on earlier experiments [32, 33, 42] reported a series of experimental results demonstrating the importance of spot cooling and between-subject individual differences for the preferred air velocity value [64].

Interaction between the different parameters of environmental quality (indoor air quality, thermal and visual comfort) was discussed in a short and interesting 1993 paper based upon experiments carried out at DTU [65]. This topic is still controversial and has not been fully investigated.

The progress of research started in the 1980s led to the publication of two original papers in 1998, devoted to the role of relative humidity $[66,67]$. These papers showed that, at thermal neutrality, humidity may affect thermal comfort due to high levels of skin humidity [66] and insufficient cooling of the mucous membranes in the upper respiratory tract caused by inhalation of humid or warm air [67]. Both papers proposed models to predict the percentage dissatisfied which were adopted to specify upper limits for humidity in indoor environments.

\section{The period from 2000 to 2006}

Fanger devoted more attention to indoor air quality during this period, but he did not forget thermal comfort and continued his research on it. In a paper published in 2002 [68] he replied to de Dear and Brager's adaptive model [69]. This approach to thermal comfort is based on the assumption that people play an instrumental role in creating their own thermal preferences through their interaction with the environment, by modifying their own behaviour, or gradually adapting their expectations to match the available thermal environment. The adaptive model was conceived to overcome the limitations of the PMV index, which overestimates the thermal discomfort caused by warm and humid climates, by making use of a simple linear regression equation that predicts the neutral temperature indoors from the monthly average outdoor temperature. Fanger and Toftum [68] suggested that such an over- 
estimation was due to expectation and to the fact that in warm climates the activity level is subconsciously reduced by people feeling warm, a potentially very powerful form of behavioural adaptation. In addition, while believing that in warm climates air-conditioning with proper thermostatic control in each space can provide better control of comfort than operable windows, Fanger and Toftum proposed an extension of the PMV model to free-running buildings in these climates by introducing the expectation factor e. This factor, multiplied by the PMV value, returns a corrected vote that takes into account the reduced expectation of comfort of the occupants of non-air conditioned environments. In this way, it is possible to take into account some adaptation in thermal environment assessment with no changes to the mechanism of heat balance of the human body or to the formulation of the PMV index.

In 2003 Fanger contributed to research on the role of clothing as a behavioural factor in thermoregulation [70].

His last paper, published in January 2006 [71] and based on experiments carried out in a novel climatic room built at DTU [72], reported the effect of variations in activity level on thermal sensation. He found that thermal sensation started to rise or decline immediately after a change of activity. After approximately 15-20 minutes of constant activity, subjective thermal responses approximated the steady-state response. The sensitivity of thermal sensation to changes in core temperature was higher for activity down-steps than for up-steps. For both up-steps and down-steps the rate of change of thermal sensation followed an exponential relationship. Finally, a model was proposed that estimates transient thermal sensation with metabolic step-changes.

These are very important results for both researchers in the field of thermal environment and HVAC designers because they demonstrate the importance of personal factors for thermal sensation.

\section{Conclusions}

Povl Ole Fanger, professor at the Technical University of Denmark, was an influential pioneer of a novel way to approach thermal comfort issues. As he stated in his first paper, his entire research activity in the field was primarily intended "To give the heating and air-conditioning engineer the necessary information from which he can predict, for any type of activity and clothing, all those combinations of thermal factors in the environment under which the largest possible percentage of a given group of people will experience thermal comfort”. His comfort equation is used today almost worldwide and the PMV index is still the foundation of several National and International Standards.

His studies dealt with almost all issues of thermal comfort: global and local thermal discomfort, parameters affected thermal sensation, adaptation, combined effects of other aspects of the indoor environmental quality (e.g. colour of the lighting or noise), measurement protocols, sensors, energy 
conservation and HVAC systems. His ability, his curiosity and his care for the well-being of occupants are further confirmed by his subsequent studies on indoor air quality that led to the formulation of an original theory that is still in use.

Several of the topics investigated by Fanger, such as adaptation and natural ventilated buildings, are still controversial (and not definitely solved), as confirmed by the current literature in the field and several researchers are working to improve the applicability of the PMV/PPD approach (e.g. by changing existing coefficients or constants in the model using new findings from field surveys).

The authors are confident that this contribution, voluntarily focused only on his own studies on thermal comfort will serve as a guiding light for researchers working on those issues both now and in the future.

\section{Funding}

Italian Ministry for Education, University and Research.

\section{Acknowledgments}

The authors wish to thank the reviewers of this paper for their constructive comments on the style, content and scope of the manuscript.

\section{References}

[1] P.O. Fanger, Calculation of thermal comfort: introduction of a basic comfort equation, ASHRAE Transactions 73(2) (1967) III.4.1-III.4.20.

[2] A.P. Gagge, A new physiological variable associated with sensible and insensible perspiration, Am J Physiol 120 (1937) 277-287.

[3] P.O. Fanger, R.G. Nevins, P.E. McNall, Predicted and measured heat losses and thermal comfort conditions for human being, Symposium on Thermal Problems in Biotechnology, ASME Symposium Series, New York (1968) 61-81.

[4] P.O. Fanger, O. Angelius, P. Kjerulf-Jensen, Radiation data for the human body, ASHRAE Transactions 76(2) (1970) 338-373.

[5] P.O. Fanger, Thermal Comfort, Danish Technical Press, Copenhagen, 1970.

[6] ISO 7730, Ergonomics of the Thermal Environment - Analytical Determination and Interpretation of Thermal Comfort Using Calculation of the PMV and PPD Indices and Local Thermal Comfort, International Standardization Organization, Geneva, 2005.

[7] S. Olesen, P.O. Fanger, Can man be adapted to prefer a lower ambient temperature? Proceedings 
of 5th International Congress for Heating, Ventilating and air Conditioning, Copenhagen (1971) 2840.

[8] P.O. Fanger, The influence of age, sex, adaptation, season and circadian rhythm on thermal comfort criteria for man, Bulletin de l’IIR, Annex 1973-2 (1973) 91-97.

[9] P.O. Fanger, N.O. Breum, E. Jerking, The effect of colour and noise on man's thermal comfort conditions, Proceedings of Symposium on Physiological requirements on the microclimate in industry and problems of their technical realizations, Prague (1975).

[10] P.O Fanger, N. Breum, E Jerking, Can colour and noise influence man's thermal comfort? Ergonomics 20 (1977) 11-18.

[11] P. Kjerulf-Jensen, Y. Nishi, P.O. Fanger, A.P. Gagge, A new type test chamber in Copenhagen and New Haven for common investigations of man's thermal comfort and physiological responses. ASHRAE Journal January (1975) 65-68.

[12] S. Olesen, J.J. Bassing, P.O. Fanger, Physiological comfort conditions at sixteen combinations of activity, clothing, air velocity and ambient temperature, ASHRAE Transactions 78(II) (1972) 199206.

[13] B.W. Olesen, P.O. Fanger, The skin temperature distribution for resting man in comfort. Archives des sciences physiologiques, 27(4) (1973) A385-A393.

[14] P.O. Fanger, Assessment of man's thermal comfort in practice, British Journal of Industrial Medicine 30 (1973) 313-324.

[15] P.O. Fanger, J. Hojbjerre, J.O.B. Thomsen, Man’s preferred ambient temperature during the day, Archives of Science Physiologiques, 27(4) (1973) A395-A402.

[16] P.O. Fanger, O. Ostberg A.G.McK. Nicholl, N.O. Breum, E. Jerking, Thermal comfort conditions during day and night, European Journal of Applied Physiology 33 (1974) 255-263.

[17] P.O. Fanger, J. Hojbjerre, J.O.B. Thomsen, Thermal comfort conditions in the morning and in the evening, International Journal of Biometeorology, 18(1) (1974) 16-22.

[18] D.P. Wyon, Th. Asgeirsdotti, P. Kjerulf Jensen, P.O Fanger, The effects of ambient temperature swings on comfort, performance and behaviour. Archives of Science Physiologiques, 27(4) (1973) A441-A458.

[19] G. Langkilde, K. Alexandersen, P. Wyon, P.O. Fanger, Mental performance during slight cool or warm discomfort. Archives of Science Physiologiques, 27(4) (1973) A511-A518.

[20] D.P. Wyon. The effects of moderate heat stress on the mental performance of children. Document D8/69, National Swedish Institute for Building Research. Stockholm: Building Research Council, 1969. 
[21] P.O. Fanger, The variability of man's preferred ambient temperature from day to day, Archives of Science Physiologiques, 27(4) (1973) A403-A407.

[22] D.P. Wyon, P.O. Fanger, B.W. Olesen, C.J.K Pedersen, The mental performance of subject clothed for comfort at two different air temperatures, Ergonomics, 18(4) (1975) 359-374.

[23] S. Olesen, P.O. Fanger, P.B. Jensen, O.J. Nielsen, Comfort limits for man exposed to asymmetric thermal radiation, Proceedings of CIB Commission W45 Symposium (1972).

[24] P.O. Fanger, J. Ostergard, S. Olesen, T.L. Madsen, The effect on man's comfort of a uniform airflow from different directions, ASHRAE Transactions 80(2) (1974) 142-157.

[25] V. Korsgaard, T.L. Madsen, New instruments for measuring thermal comfort. Proceedings of the 13th International Congress of Refrigeration, Washington D.C., (1971) 313-322.

[26] P.O. Fanger, C.J.K. Pedersen, Discomfort due to air velocities in spaces, Proceedings of Commission B1, B2, E1 of IIR (1977) 289-296.

[27] B.W. Olesen, M. Scholer, P.O. Fanger, Discomfort caused by vertical temperature differences. In: Indoor climate, Copenhagen, Danish BRI (1979) 561-579.

[28] P.O. Fanger, G. Langkilde, Interindividual differencies in ambient temperatures preferred by seated persons, ASHRAE Transactions 81(2) 1975 140-147.

[29] P.O Fanger, Comfort at workplaces by spot cooling, Proceedings of XIV International Congress of Refrigeration, Moscow, September 1975, pp. 683-690.

[30] B.W. Olesen, H. Arkin, Individual cooling at hot workplaces, Proceedings of XV International Congress of Refrigeration, Venice, September 1979.

[31] B.W. Olesen, R. Nielsen, Radiant spot cooling of hot places of work. ASHRAE Transactions 87(1) (1981) 593-608.

[32] A. Shitzer, E.B. Rasmussen, P.O. Fanger, Human responses during recovery from heat stress with relation to comfort, Ergonomics 21(1) (1978) 21-34.

[33] P.O. Fanger, Future research needs concerning the human response to indoor environments. ASHRAE Transactions 84(1) (1978) 760-764.

[34] T.L. Madsen, A new instrument for measuring thermal comfort. Proceedings of Heating, Ventilating and Air Conditioning, Copenhagen, 1971, 109-126.

[35] P.O. Fanger, Danish Indoor Climate Research, Danish HVS magazine 11 (1983).

[36] P.O. Fanger, Thermal Environments human requirements, Sulzer Technical Review (1985).

[37] P.O. Fanger, Fundamentals of thermal comfort. Proceedings of Biennal Congress of the International Solar Energy Society, Hamburg, September 1987, pp. 3056-3061.

[38] P.O. Fanger, L. Bànhidi, B.W. Olesen, G. Langkilde, Discomfort caused by overhead radiation. Proceedings of Clima 2000 Symposium, Budapest September 1980, pp. 65-74. 
[39] P.O. Fanger, L. Bànhidi, B.W. Olesen, G. Langkilde, Comfort limits for heated ceilings. ASHRAE Transactions 86(2) (1980) 141-156.

[40] P.O. Fanger, Prediction of local discomfort for man. Studies in Environmental Science 10(C) (1981) 221-227.

[41] P.O. Fanger, N.K. Christensen, Perception of draught in ventilated spaces, Ergonomics 29(2) (1986) 215-235.

[42] P.O Fanger, A.K. Melikov, H. Hanzawa, J. Ring, Air turbulence and sensations of draught, Energy and Buildings 12(1) (1988) 21-39.

[43] H. Hanzawa, A.K. Melikov, P.O Fanger, Airflow characteristics in the occupied zone of ventilated spaces, ASHRAE Transactions 93(1) (1987) 523-539.

[44] A.K. Melikov, H. Hanzawa, P.O. Fanger, Airflow characteristics in the occupied zone of heated spaces without mechanical ventilation, ASHRAE Tran 94(1) (1988) 52-70.

[45] N.K. Christensen, O. Alberchtsen, P.O. Fanger, Air movement and draught, Proceedings of Indoor Air Congress, Stockolm August 1984 20-24.

[46] B.W. Olesen, E. Sliwinska, T.L. Madsen, P.O. Fanger, Effect of body posture and activity on the thermal insulation of clothing: measurement by a movable thermal manikin, ASHRAE Transactions 88(2) (1982) 791-805.

[47] R. Nielsen, B.W. Olesen, P.O. Fanger, Effect of physical activity and air velocity on the thermal insulation of clothing, Ergonomics 28 (1985) 1617-1631.

[48] P.O. Fanger, The effect of air humidity in buildings on man's comfort and health. Proceedings of the CISCO-ITBTP Seminar "Humidity in building”, Saint Remy les Chevreuse, November 1982. [49] P.O. Fanger, Air humidity, comfort and health, Proceedings of IIR Commission E1, 1983 192195.

[50] P.O. Fanger, Human comfort aspects of different heating systems. Proceedings of EURORAD Assembly meeting, Palma de Mallorca, May 1984.

[51] B.W. Olesen, 1980. Energy consumption and thermal comfort in a room heated by different methods”, Proceedings of 7th International Congress of Heating and Air-Conditioning "Clima-2000", Budapest, 1980.

[52] B.W. Olesen, E. Mortensen, J. Thorshauge, B. Berg-Munch, Thermal comfort in a room heated by different methods, ASHRAE Transactions, 86(1) (1980) 34-48.

[53] P.O. Fanger, The philosophy behind a comfort standard, Proceedings of the Indoor Air Symposium, 1984 20-24.

[54] P.O. Fanger, The PMV-index and the international comfort standard: practical applications. Proceedings of AiCARR Seminar, Napoli (Italy) 1986 May $31^{\text {th }}$. 
[55] P.O. Fanger, Thermal comfort in clean rooms. Proceedings of "Fortschritte der Reinraumtechnik”, Frankfurt am Main, June 1985.

[56] P.O. Fanger, Ventilation and thermal comfort for athletes and spectators. Proceedings of REHVA Seminar, 1986 December, $5^{\text {th }}$.

[57] ISO 7730, Moderate thermal environment - Determination of the PMV and PPD indices and specification of the condition for thermal comfort, Geneva: International Standardization Organization, 1984.

[58] P.O. Fanger, Thermal comfort requirements, Proceedings of the Meeting "Les applications du thermoconditionnement à la thermique des batiments”, Lyon, 1983.

[59] B.W. Olesen, Thermal Comfort Requirements for Floors Occupied by People with Bare Feet, ASHRAE Transactions 83 (1977) 41-57.

[60] B.W. Olesen, Thermal comfort requirements for floors. Proceedings of Commission B1, B2, E1 of IIR, 1979

[61] P.O. Fanger, Introduction of the olf and the decipol units to quantify air pollution perceived by humans indoors and outdoors, Energy and Buildings 12 (1988) 1-6.

[62] H.N. Knudsen, P.O. Fanger, The impact of temperature step-changes on thermal comfort, Proceedings of 5th International Conference on Indoor Air Quality and Climate, Indoor Air 1990 757761.

[63] R.J. de Dear, J.W. Ring, P.O. Fanger, Thermal sensations resulting from sudden ambient temperature changes. Indoor Air 3 (1993)181-192.

[64] A.K. Melikov, R.S. Arakelian, L. Halkjaer, P.O. Fanger, Spot cooling-Part 1: human responses to cooling with air jets. ASHRAE Transactions 100(2) (1994) 101-124.

[65] G. Clausen, L. Carrick, P.O. Fanger, S.W. Kim, T. Poulsen, J.H. Rindel , What causes discomfort? Building Services, June 1993 47-48.

[66] J. Toftum, A. Jorgensen, P.O. Fanger, Upper limits of air humidity to avoid uncomfortable humid skin, Energy and Buildings 28 (1998) 1-13.

[67] J. Toftum, A. Jorgensen, P.O. Fanger, Upper limits of air humidity for preventing warm respiratory discomfort. Energy and Buildings, 28 (1998) 15-23.

[68] P.O. Fanger, J. Toftum, Extension of the PMV model to non-air-conditioned buildings in warm climates, Energy and Buildings 34 (2002) 533-536.

[69] R.J. de Dear, G.S. Brager, Developing an adaptive model of thermal comfort and preference, ASHRAE Transactions 104(1a) (1998) 145-167.

[70] T. Goto, J. Toftum, P.O. Fanger, H. Yoshino, Transient thermal sensation and comfort resulting from adjustment of clothing insulation. Proceedings of Healthy Buildings Congress, Singapore 2003 
December, 835-840.

[71] T. Goto, J. Toftum, R.J. de Dear, P.O. Fanger, Thermal sensation and thermophysiological responses to metabolic step-changes, International Journal of Biometeorology 50(5) (2006) 323-332. [72] J. Toftum, G. Langkilde, P.O. Fanger, New indoor environment chambers and field experiment offices for research on human comfort, health and productivity at moderate energy expenditure. Energy and Buildings 36 (2004) 899-903. 